\title{
USING SPATIO-TEMPORAL MODELLING AS A DECISION SUPPORT TOOL FOR MANAGEMENT OF A NATIVE PEST HERBIVORE
}

\author{
WIGGINS, N.L. ${ }^{1^{*}}-$ PENNY, S. ${ }^{2}-$ BOWMAN, D.M.J.S. ${ }^{1}-$ COLLIER, N ${ }^{3}{ }^{3}$ \\ McMAHON, C.R. ${ }^{4}$ \\ ${ }^{1}$ University of Tasmania, School of Plant Science \\ Hobart, TAS Australia 7001 \\ ${ }^{2}$ Department of Primary Industry and Fisheries, Berrimah Farm \\ Darwin, NT Australia 0801 \\ ${ }^{3}$ Edith Cowan University, Faculty of Computing, Health and Science \\ Perth, WA Australia 6027 \\ ${ }^{4}$ School for Environmental Research, Charles Darwin University \\ Darwin, NT Australia 0810 \\ ${ }^{*}$ Corresponding author \\ e-mail:wigginsn@utas.edu.au \\ (Received $2^{\text {nd }}$ July 2013 ; accepted $22^{\text {nd }}$ July 2014)
}

\begin{abstract}
Landscape modification can alter the distribution and abundance of wildlife, which can result in irruptions of native species causing significant impacts on economically and ecologically valuable systems. This study investigated the applications of the Spatio-Temporal Animal Reduction (STAR) model, originally designed for the management of feral ungulates, by adapting it for the management of a native pest herbivore (the Tasmanian pademelon, Thylogale billardierii) within an agricultural-forest mosaic, typical of Tasmanian (Australian) agricultural landscapes. Empirical data of habitat and demographic features of a pest population were inputted into STAR to test the cost-effectiveness of three simulated density reduction models. Compared with the projected population growth under no management, simulations demonstrated that low, medium and high density reduction all reduced population abundance over 10 years. Cost increased with the level of population reduction due to increasing difficulty with locating individuals. The revenue gained from a simulated harvest was greatest for medium-intensity density reduction. We propose STAR can be used as a decision support tool to guide situations considering resource availability, browsing intensity and site-specific management objectives. The application of STAR highlights the model's adaptability across diverse pest populations, landscape features and where there is competition for resources between domestic and native populations. Keywords: decision support tool, native herbivore, pest species, spatio-temporal model, wildlife management
\end{abstract}

\section{Introduction}

Human population growth necessarily results in an increasing demand for resources (e.g. mineral, agricultural and residential), and this causes global conflict between humans and wildlife (Vitousek et al., 1997; Chapin et al., 2000; Weinbaum et al., 2012). Given the high demand for food, this conflict is often most obvious and vigorous at the agricultural-wild land interface (Edwards et al., 1996; Viggers and Hearn, 2005). The modification and development of landscapes for economically valuable systems inadvertently alters the distribution and abundance of native species (Rounsevell et al., 1991; Edwards et al., 1996). Importantly, such agricultural intensification often results 
in irruptions of pest species, through the reduction in natural enemies, an increase in the scale of cultivation, and a decline of host plant defences (Soroush, 2010). In some situations, agricultural development may cause increases in the abundance of some native herbivores species. This often occurs where fragments of native vegetation provide shelter adjacent to improved pasture and water points (Calaby and Grigg, 1989; Rounsevell et al., 1991). The browsing and grazing pressures exerted by native herbivores on managed land can result in significant costs associated with economic productivity and environmental management (e.g. Coleman et al., 1997; Bulinski and McArthur, 1999; Torstenson et al., 2002).

The management of pest species generally attempts to decrease population numbers below a critical damage threshold level (Shea et al., 1998; McMahon et al., 2010). In order to achieve this, determination of an acceptable level of damage and its relationship to pest density across the landscape is required (Buckley et al., 2004; Edwards et al., 2004), in combination with the selection of the most cost effective management strategies available (Buckley et al., 2004). The suppression of population densities of native pest herbivores remains difficult across the Australian landscape, and the critical damage threshold may shift in response to localised features, as $(i)$ native herbivore species have large population densities at the interface of managed landscapes, necessitating extensive, large-scale and highly coordinated management approaches to keep population numbers low (McMahon et al., 2010); (ii) the cost of management increases with decreasing animal densities (Bayliss and Yeomans, 1989); (iii) pest herbivore species may display cryptic and/or nocturnal behaviour, which can make access and control strategies challenging and costly (Coleman et al., 1997; le Mar and McArthur, 2001); (iv) management practices attract socio-political scrutiny and regulation, including modified approaches to lethal density reduction strategies traditionally adopted for invasive species management (Coleman et al., 1997; Buckley et al., 2004) and the implementation of alternative non-lethal control strategies (Coleman et al., 2006; Day and MacGibbon, 2007; Wiggins et al., 2010); and (v) follow-up monitoring of population densities and the effectiveness of the management strategy is often not always performed or practical to do so (McMahon et al., 2010).

An improved approach to the control of population densities of native pest herbivores may be aided by the development of decision support tools using spatiotemporal explicit models which can identify near optimal cost-effective removal strategies of pest species. Such tools enable improved management planning by combining information on pest population dynamics, associated financial costs and landscape/habitat structure. Moreover, spatio-temporal models have the capacity to inform managers on the likely behavioural movement of animals into (and out of) control areas and population densities relative to preferred habitat type. By taking immigration (and emigration) movements into account, management can be targetspecific to problematic areas. Additionally, simulation models allow for updates to control strategies as new knowledge is acquired (Haule et al., 2002; Bradshaw and Brook, 2007; McMahon et al., 2010). It is desirable, and often essential, for pest management strategies to minimise the cost-benefit ratio of the control strategy. Modelling important ecological and economic factors allows researchers and managers to explore a range of cost-benefit outcomes as a result of contrasting management approaches.

The Spatio-Temporal Animal Reduction (STAR) model provides a practical decision support tool that explores the biological, logistical and financial consequences of 
density reduction management scenarios in a virtual landscape (McMahon et al., 2010). STAR provides a virtual framework for making informed comparisons of different management scenarios, thereby identifying the minimum proportion of the pest population to be removed for effective population control; identifying habitat-specific problem areas and optimal control techniques to be used; and incorporating information on the spatial and temporal costs of pest species density reduction. It is a user-friendly tool that allows managers to update new data and changing economic conditions (McMahon et al. 2010). The flexibility of STAR may therefore enhance the use of adaptive management principles in which the results of management actions (e.g. experiments) inform future planning and decision-making (e.g. Bradshaw et al., 2007; McCarthy and Possingham, 2007).

A concrete example of the need to trial new management approaches concerns the management of native pest herbivores in Tasmanian agricultural landscapes. The use of 1080 poison to control pest populations is currently being phased out across the Tasmanian landscape, in response to social concerns over the environmental impact of this poison on non-target species. Alternative wildlife management strategies are currently being sought and tested (e.g. Coleman et al., 2006). While alternative management strategies may provide socially preferred means for mitigating browsing damage across the landscape, their cost-effectiveness and execution is generally not considered to offer the same level of cost-effectiveness as density reduction strategies through broad-scale lethal (i.e. 1080 poison) control (Coleman et al., 2006).

The aim of this research was to investigate the utility of the Spatio-Temporal Animal Reduction (STAR) model (McMahon et al., 2010) in the management of a native pest herbivore within an agricultural-forest mosaic. We investigated a browsing macropod, the endemic Tasmanian pademelon (Thylogale billardierii), which is commonly distributed across the Tasmanian landscape as a case study to adapt and test the applications of STAR. A combination of factors likely contribute to the widespread distribution and abundance of pademelons in Tasmanian, including a shift in landscape structure toward a more extensive agricultural-forest mosaic post-European settlement (e.g. Calaby and Grigg, 1989, Rounsevell et al., 1991) and the recent removal or declines in densities of top-order predators from the system (Figueirido and Janis, 2011, Hamede et al., 2013). Specifically, we aimed to (i) input habitat and demographic data collected from of a native pest population into the STAR model; and (ii) test the costeffectiveness of a range of density reduction management strategies targeting the control of a native pest population. We provide a range of simulated models based on a wildlife management strategy (culling) adopted across the Tasmanian landscape relevant to macropod herbivore management, and provide a case study which contributes to testing the adaptability and flexibility of the STAR model across a diversity of pest populations and landscape features.

\section{Materials and Methods}

\section{Target native pest species}

The Tasmanian pademelon (Thylogale billardierii), at high densities, can cause extensive damage to managed landscapes including agricultural and forestry industries (Coleman et al., 1997; le Mar and McArthur, 2001). Pademelons are small, sexually dimorphic macropods that display cryptic behaviour and are predominately crepuscular (most active at dawn and dusk) (le Mar and McArthur, 2001; Wiggins et al., 2010). The 
distribution of the Tasmanian pademelon is widespread and common throughout the Tasmanian landscape, with population densities reported as highest in areas where agricultural land is adjacent to native forest (Rounsevell et al., 1991). The total area of agricultural land within $1 \mathrm{~km}$ of eucalypt forest in Tasmania is 925,080 ha, which occurs across $14 \%$ of the total landscape area (TASVEG, 2005; Fig. 1).

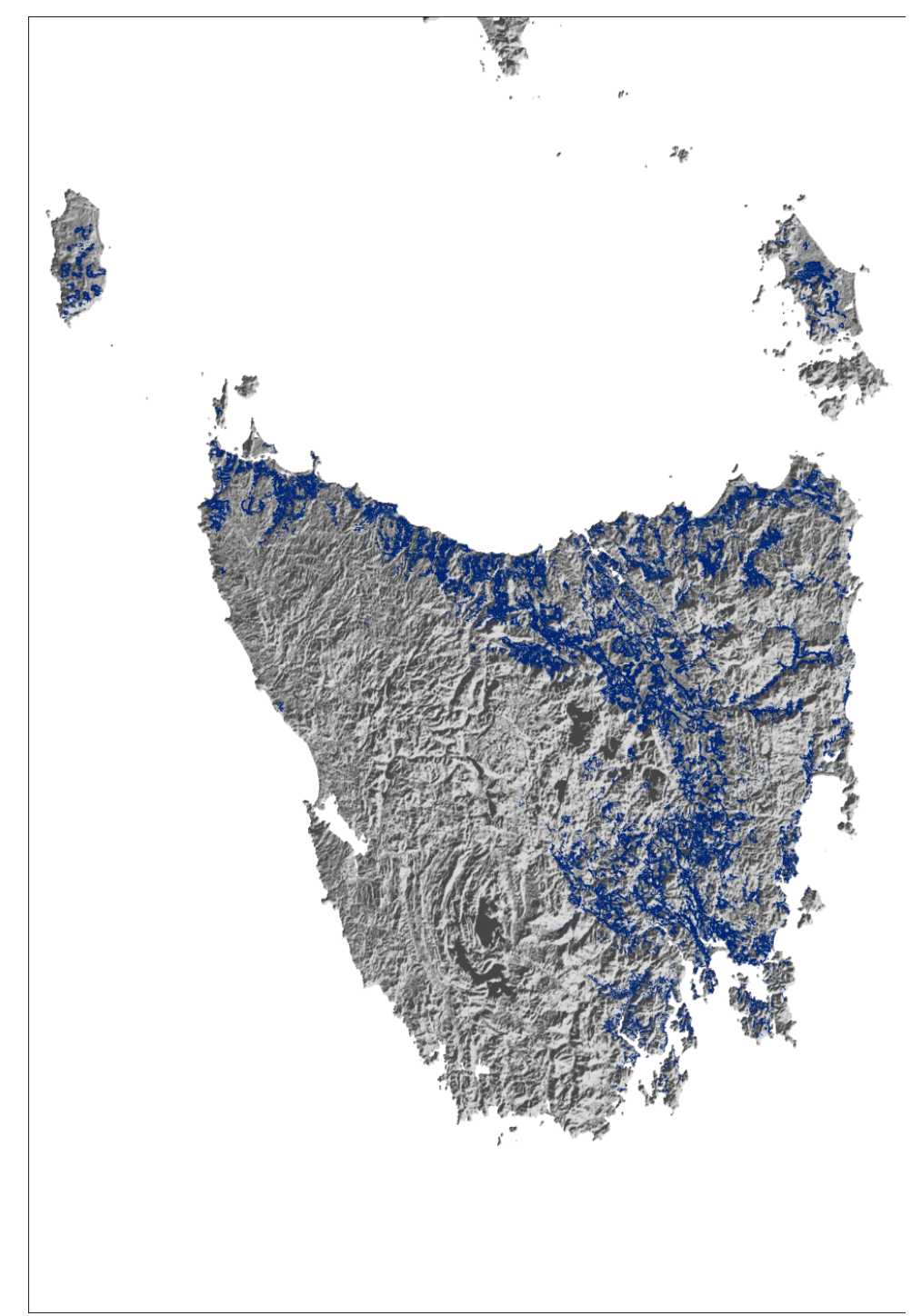

Figure 1. The total area of agricultural land within $1 \mathrm{~km}$ of eucalypt forest in Tasmania, including the Bass Straight Islands (calculations derived from TASVEG, 2005).

\section{Habitat structure}

A $2 \times 2 \mathrm{~km}$ cell grid of the study site was constructed, using habitat features derived from habitat surveys and TASVEG (2005) (see Wiggins and Bowman, 2011 for additional detail), to create a vector grid for use in the STAR model (Appendix). This grid features in output models created using STAR, which is used to display animal responses to proposed management scenarios. In total, 187 cells comprised the study site, giving an overall area of $748 \mathrm{~km}^{2}$. 


\section{Model structure}

STAR was originally written as an interactive Microsoft Excel ${ }^{\circledR}$ spreadsheet-based model (using Visual Basic for Applications (VBA) language) designed to be a user friendly, ecologically realistic tool for pest management applications. Specific details of model structure, coding and user manual access are described in McMahon et al. (2010). The model presented here has been modified to incorporate the landscape configuration of our study site in Scottsdale, north-eastern Tasmania, Australia $\left(41^{\circ} 06^{\prime} \mathrm{S}, 14735^{\prime} \mathrm{E}\right)$, based on a cellular lattice framework, and is thus spatially explicit with respect to habitat type, elevation and landscape terrain relevant to this, and similar agricultural-forest mosaic areas across the Tasmanian landscape (Wiggins and Bowman, 2011). These features can have important implications on management approaches (and therefore success) as heterogeneous landscapes can alter access to, and costs associated with, animal management in both targeted and adjacent cells. The model structure uses density-feedback and economic cost functions to calculate the cost-benefit ratios of proposed management scenarios (detailed in McMahon et al., 2010) and has been updated to incorporate cost-benefit functions relative to the proposed management scenarios currently practiced in Tasmania (Wiggins et al., 2010). Briefly, animal density is represented as a numeric response between the following parameters in the STAR model: habitat carrying capacity, rate of recruitment, rate of immigration and emigration, culling rate, spatial and temporal variation in landscape features and management-specific costs, location, time-frame, frequency and benefits (i.e. commercial harvesting). A comprehensive explanation of specific cell mechanics is presented in McMahon et al., (2010), where each cell in the grid acts as a specific unit within the overall dynamics of the study area and can be influenced by surrounding cell parameters. Thus, the model is habitat driven in that animal densities are ultimately linked to the habitat quality of the region of interest. The change in animal numbers in each individual cell is governed by the following equation $(E q .1)$ :

$$
N_{i j, t+1}=N_{i, j, k} e^{r_{m}\left[1-\left(\frac{N_{i n}}{B_{i j}}\right)^{n}\right]}-C_{i j}-\left(E_{i j}-I_{i j}\right)
$$

where $i$ is the cell row number in the study site cell grid, $j$ is the cell column number, $t$ is the time interval, $N_{i, j, t+1}=$ number of animals in cell $i, j$ at the next time interval $(t+1)$, $N_{i, j, t}=$ number of animals in cell $i, j$ at time interval $t, r_{m}=$ maximum rate of population increase when resources are not limiting, $K_{i, j}=$ habitat-specific maximum carrying capacity, è is a shape parameter that modifies the relationship between $r$ and population size $(N), C_{i, j}=$ total number of animals culled in cell $i, j, E_{i, j}=$ total number of animals emigrating from cell $i, j$, and $I_{i, j}=$ total number of animals immigrating into cell $i, j$ (McMahon et al., 2010).

\section{Management scenarios}

Within the suite of pre-specified management scenarios designed to simulate pest population management options in STAR, we tested four density targets that aim to reduce densities to specified targets over large areas (also tested in McMahon et al., 2010 for invasive species management). The culling technique, lethal control by a trained marksman using a spotlight, is based on current practices routinely used across 
the Tasmanian landscape (Coleman et al., 2006; Wiggins et al., 2010). The density targets included $(i)$ zero density reduction to examine how populations are expected to change over time under no management intervention and provide a comparative (control) simulation ( 0 animals removed); (ii) low-intensity density reduction (17\% initial cull rate and $9 \%$ follow-up cull rate per year); (iii) medium-intensity density reduction (30\% initial cull rate and $19 \%$ follow-up cull rate per year); and (iv) highintensity density reduction (50\% initial cull rate and $31 \%$ follow-up rate per year). These scenarios enable comparisons of the cost-effectiveness of low- to high-intensity density reduction operations across the agricultural study site over a 10-year management period, selected to represent a timeframe relevant to an individual land manager. Follow-up cull rates were derived from McMahon et al., (2010) to achieve the pre-defined density-reduction targets over the specified management timeframe, but can be modified to best suits individual user interests or needs.

Under natural population conditions (i.e. no management regime), populations that exist below ecological carrying capacity (as predicted for pademelons at our study site) would be expected to reach high densities across the majority of the landscape (Coulson et al., 2004). Following on from this prediction, low-intensity management would be expected to create high density areas which may have a greater potential to fill any 'gaps' in population distribution, as animals in areas of high densities will naturally filter into areas of lower densities, given similar levels of habitat suitability (; Porter et al., 1991; Efford et al., 2000). How long any created gaps will persist in the environment is a direct function of the intrinsic growth potential of the population and the scale of the management intervention (Efford et al., 2000, Wiggins et al., 2010). There is the potential that if density reduction is performed at too low a level, the management strategy may generate a steady increase in population numbers across the landscape, thus having little or no net effect on population density (Caughley, 1985). Medium- and high-intensity management strategies would be expected to achieve a greater reduction in high density areas across the landscape.

Within each scenario, we compared $(a)$ the total number of animals removed and remaining after culling; $(b)$ the associated culling cost per animal and total management costs; and $(c)$ the offset to costs, which aimed to calculate the revenue obtained from a commercial-based culling operation.

\section{Model parameters}

The following model parameters were standardised across each of the scenarios: The carrying capacity $K$ for each habitat type was set at 177 animals per square $\mathrm{km}$ in agricultural habitat, 44 animals per square $\mathrm{km}$ in native forest habitat and 89 animals per square $\mathrm{km}$ for all other habitat types (DPIPWE Density Indices, 2009). The relative suitability of each habitat type was set at $57 \%$ for agricultural habitat, $15 \%$ for native forest habitat and $28 \%$ for all other habitat types (Wiggins et al., 2010). It was assumed that the habitat mosaic remained unchanged through the study period. The initial population size - the proportion (fraction) of $K$ - was set to 0.5 , which set the habitatspecific carrying capacities in the cells occupied by pademelons to $50 \%$ of the maximum, giving initial population densities of 88 animals per square $\mathrm{km}$ in agricultural habitat, 22 animals per square $\mathrm{km}$ in native forest habitat and 44 animals per square $\mathrm{km}$ for all other habitat types. This value was guided by knowledge of previous and current density reduction strategies used in the area (Wiggins et al., 2010, Wiggins and Bowman, 2011) and population demographic features (McMahon et al., 
2011), indicating the population was not at carrying capacity. An average density of 51 animals per square $\mathrm{km}$ was calculated from the above parameters and the total population number, current $N$, was 39,000 animals across the entire $748 \mathrm{~km}^{2}$ management zone. The maximum annual growth rate of the population was estimated at 0.17 (McMahon et al., 2011) and the maximum dispersal rate of animals was set at 0.50 (with a maximum dispersal rate of 1 possible) to account for varying levels of immigration and emigration rates (specific to each cell) that a natural population may display. Dispersal is limited to adjacent cells per season and enables the user to test the effect of dispersal rate, particularly if it is not known, by incorporating different rates as part of the model building phase.

The cost (quoted in Australian dollars) of culling was set at $\$ 150$ per hour with overheads estimated at $50 \%$, incorporating equipment hire/use, consumables and additional labour costs. A revenue value of $\$ 2$ was assigned as the market value per individual to test the offset to costs, to examine the viability of a revenue-based trade in wallaby products such as meat (e.g. Wilson and Edwards, 2008).

\section{Results}

\section{STAR density reduction outputs}

This study tested four simulated models chosen to replicate a range of management strategies currently applied across the Tasmanian landscape:

\section{Zero density reduction}

Average population size was predicted as 53,740 individuals within the specified study area over 10 years in response to no management (Table 1, Fig. 2), taking into account population growth estimates (McMahon et al., 2011). This represents a $25 \%$ increase in population size from the initial projected population. Animal abundance was predicted as high across $60 \%$ of the mapped landscape (Fig. 3).

Table 1. STAR model output for simulated management scenarios of zero-, low-, mediumand high-intensity animal removal strategies.

\begin{tabular}{|c|c|c|c|c|}
\hline Manage ment sce nario & $\begin{array}{l}\text { Animals removed / } \\
\text { Animals remaining } \\
\end{array}$ & $\begin{array}{l}\text { Cost per animal } \\
\text { AUS }\end{array}$ & $\begin{array}{l}\text { Total manage ment } \\
\text { cost AUS }\end{array}$ & $\begin{array}{l}\text { Offs et to costs } \\
\text { AUS }\end{array}$ \\
\hline (i) Zero density reduction & $0 / 53,740$ & 0.00 & 0 & 0 \\
\hline (ii) Low-intensity reduction & $39,430 / 43,390$ & 0.29 & 11,376 & 67,312 \\
\hline $\begin{array}{l}\text { (iii) Medium-intensity } \\
\text { reduction }\end{array}$ & 63,960 / 32,860 & 0.41 & 25,996 & 101,921 \\
\hline (iv) High-inte nsity reduction & $71,230 / 20,880$ & 0.73 & 52,126 & 90,334 \\
\hline
\end{tabular}

average cost per animal culled; ${ }^{2}$ offset to costs of the density-reduction (culling) strategy provided from commercial-based culling operations.

\section{Low-intensity density reduction}

Average population size was predicted to reach 43,390 individuals within the specified study area over 10 years in response to low-intensity management (Table 1, Fig. 2). This represents a $10 \%$ increase in population size from the initial projected population. A total of 39,430 individuals were culled during the 10 year timeframe at a total cost of $\$ 11,376$ (Table 1, Fig. 2). 
Total number of animals

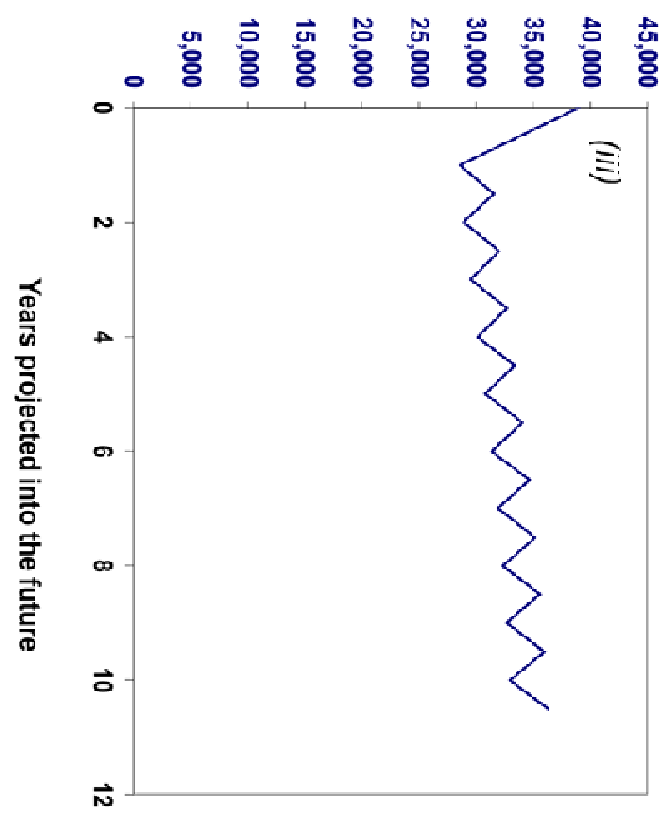

Total number of animals

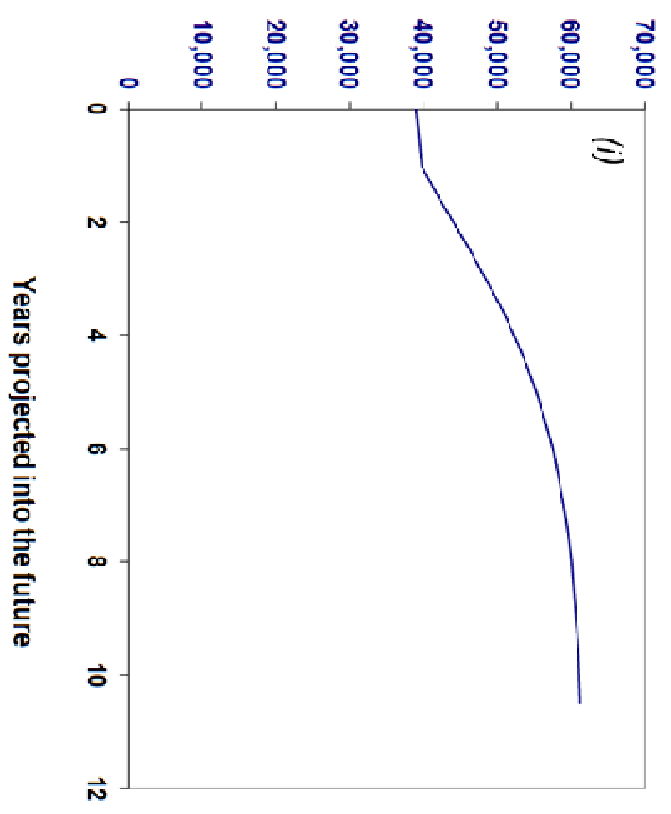

Total number of animals

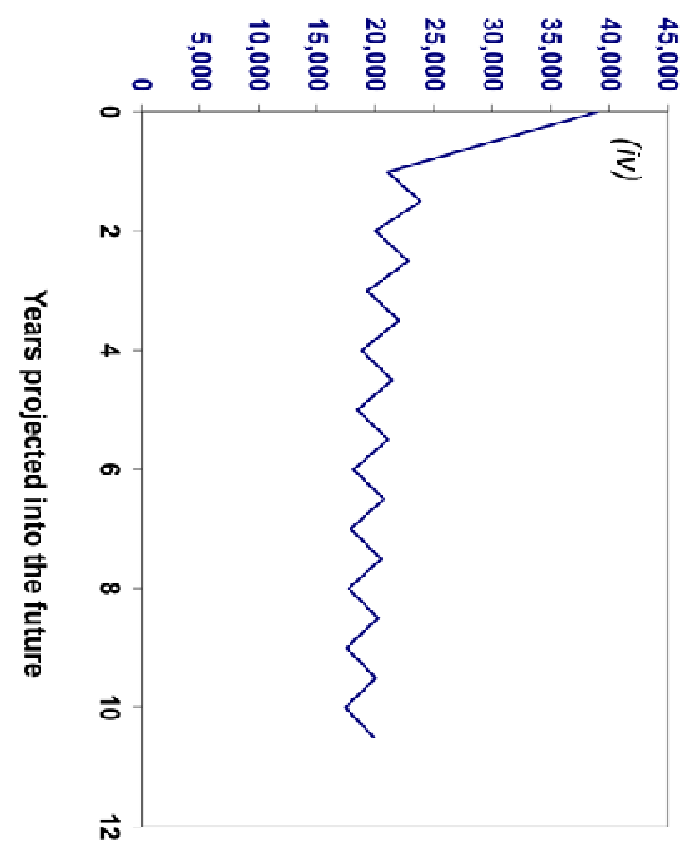

Total number of animals

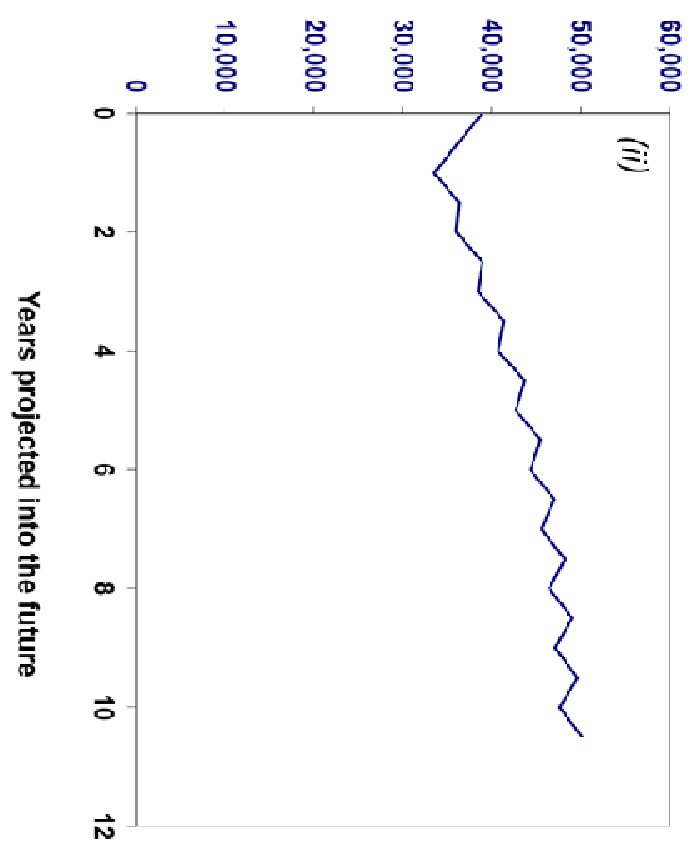

Figure 2. Population reduction strategies of (i) zero density reduction; (ii) low-intensity density reduction; (iii) medium-intensity density reduction; and (iv) high-intensity density reduction strategies for the management of a pest herbivore population (the Tasmanian pademelon Thylogale billardierii) across a heterogeneous landscape over a 10 year management period 

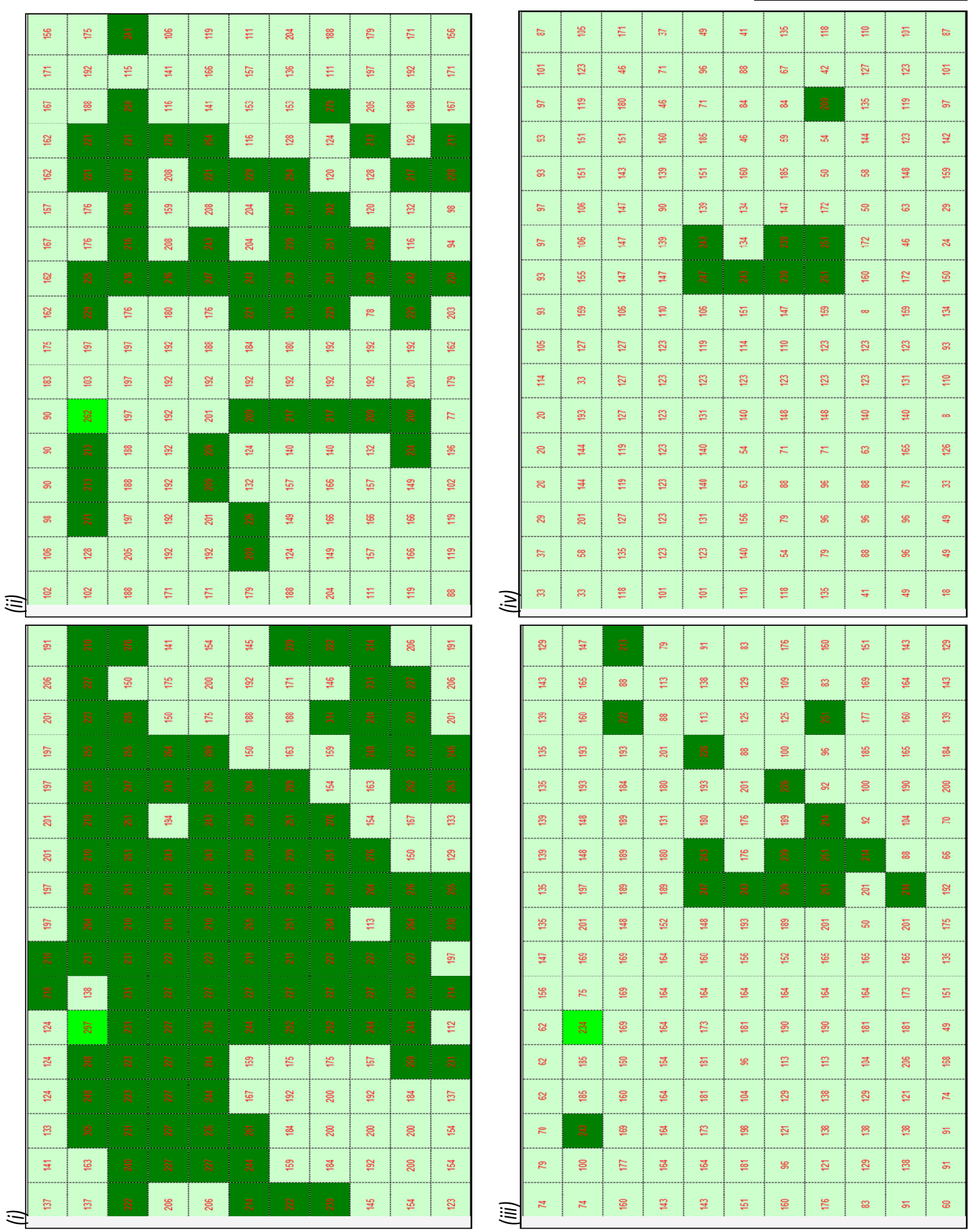

Figure 3. Population abundance of a pest herbivore (the Tasmanian pademelon Thylogale billardierii) in response to (i) zero density reduction; (ii) low-intensity density reduction; (iii) medium-intensity density reduction; and (iv) high-intensity density reduction scenarios in the study site over a 10 year management period. Note: density level categories indicated by multiple shades of green represent low, medium-low, medium and high density levels. 
Animal abundance was predicted as high across $28 \%$ of the landscape, which equates to a $53 \%$ reduction in high abundance cells compared with zero density reduction (Fig. 3). The culling cost per individual ( $\$$ individual culled ${ }^{-1}$ ) increased to a peak value of $\$ 0.36$ individual $^{-1}$ in year 2 , then gradually decreased to $\$ 0.25$ individual $^{-1}$ from year 7 (average cost $\$ 0.29$ individual $^{-1}$; Fig. 4). The total revenue gained (offset of culling costs) from a market value of $\$ 2$ per individual was $\$ 67,312$ over 10 years.

\section{Medium-intensity density reduction}

Average population size was predicted to reach 32,860 individuals within the specified study area over 10 years in response to medium-intensity management (Table 1, Fig. 2). This represents a $16 \%$ decrease in population size from the initial projected population. A total of 63,960 individuals were culled during this timeframe at a total cost of $\$ 25,996$ (Table 1, Fig. 2). Animal abundance was predicted as high across $9 \%$ of the landscape, which equates to a $69 \%$ reduction in high density cells compared with low-intensity reduction, and an $86 \%$ reduction compared with zero intensity reduction (Fig. 3). The culling cost per individual increased to a peak value of $\$ 0.45$ individual $^{-1}$ in years 2 and 3 , which decreased to $\$ 0.40$ individual $^{-1}$ from year 9 (average cost $\$ 0.41$ individual $^{-1}$; Fig. 4). The total revenue gained was $\$ 101,921$ over 10 years.

\section{High-intensity density reduction}

Average population size was predicted to reach 20,880 individuals within the specified study area over 10 years in response to high-intensity management (Table 1 , Fig. 2). This represents a $54 \%$ decrease in population size from the initial projected population. A total of 71,230 individuals were culled within this timeframe at a total cost of $\$ 52,126$ (Table 1, Fig. 2). Animal abundance was predicted as high across $4 \%$ of the landscape, which equates to a $50 \%$ reduction in high density cells compared with medium-intensity reduction, and a $93 \%$ reduction compared with zero intensity reduction (Fig. 3). The culling cost per individual started at the lowest value of $\$ 0.32$ individual $^{-1}$ in year 1 , and increased annually to a peak value of $\$ 1.01$ individual $^{-1}$ in year 10 (average cost $\$ 0.73$ individual $^{-1}$; Fig. 4). The total revenue gained was $\$ 90,334$ over 10 years.

\section{Discussion}

The Spatio-Temporal Animal Reduction (STAR) model provides a practical decision support tool to explore the biological, logistical and financial consequences of density reduction management in a virtual landscape (McMahon et al., 2010). While STAR was originally designed for the management of feral ungulates in the World Heritage Kakadu National Park (Australia), this study examined an applied case study of the model to test its applicability across a different set of pest population dynamics and landscape features. Density-reduction applications of STAR were tested to aid in the strategic management of a native marsupial pest herbivore, the Tasmanian pademelon Thylogale billardierii, in an agricultural-forest mosaic that has resulted in rapid increases in the abundance of macropod herbivores (Rounsevell et al., 1991; Viggers and Hearn, 2005; Coulson, 2009). 

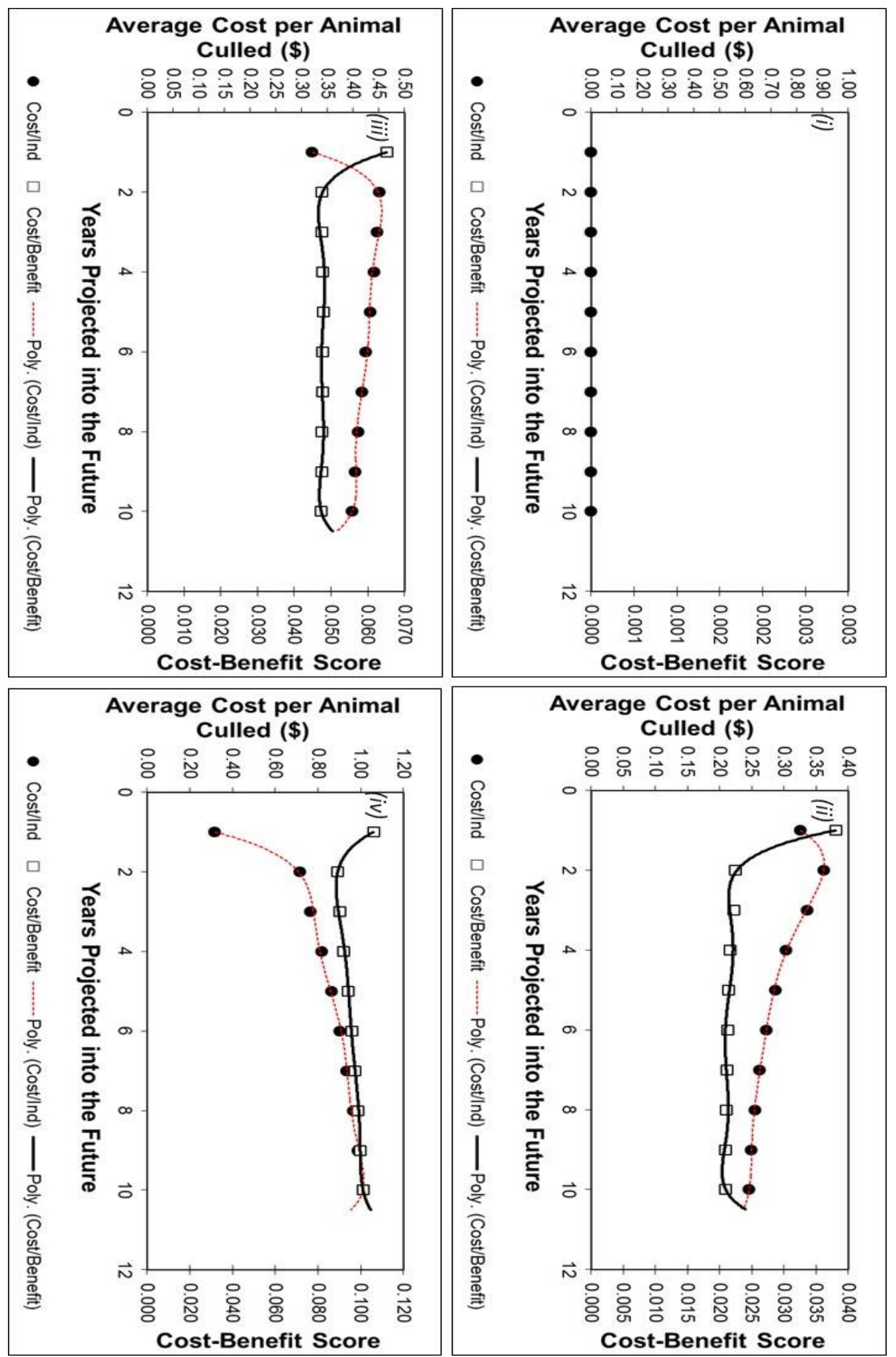

Figure 4. Average cost of culling animals (AU\$individual culled-1) and predicted cost-benefit score for the population reduction strategies of (i) zero density reduction; (ii) low-intensity density reduction; (iii) medium-intensity density reduction; and (iv) high-intensity density reduction scenarios for the management of a pest herbivore population (the Tasmanian pademelon Thylogale billardierii) across a heterogeneous landscape over a 10 year management period. 
The low, medium and high density reduction simulations were all effective at reducing population abundances compared to no management, while comparison to the initial population parameter (current $N$ ) yielded a population increase for low density reduction. With increasing density reduction targets (low- to high-intensity), greater density reductions and cost-benefit scores were achieved, but there were increasing associated costs driven by the higher-intensity management objectives. The average per capita cost per individual culled increased with increasing density reduction targets, resulting in the offset to culling costs (revenue gained) being greatest for medium density reduction. The lower population size achieved under high density reduction is likely to correlate with increasing difficulty (and therefore cost) associated with locating (and culling) individuals at low densities (e.g. Lurz et al., 2008; Fitzpatrick et al., 2009).

\section{Selection of an appropriate density reduction management strategy}

Model predictions indicated that under natural population conditions under no management regime, pademelons reached high densities across the majority of the landscape, indicating the population exists below ecological carrying capacity (Coulson et al., 2004). Low-intensity management predicted pademelons would reach high densities across one third of the landscape. While low-intensity management may be an appealing strategy in situations of limited resource availability (i.e. time or budgetary constraints), medium- and high-intensity management strategies achieved a greater reduction in high density areas across the landscape. The medium-intensity density reduction strategy offered the most cost-effective scenario for the management of Tasmanian pademelons in an agricultural-forest mosaic, a habitat interface which is representative of managed landscapes across the Tasmanian environment (Fig. 1).

There are, however, a variety of factors which need to be considered when developing a wildlife management plan for the control or conservation of a species. Selection of an appropriate management strategy commonly includes an integrated approach of planning, implementation and adaptive management features (e.g. Gibbs et al., 1999). Cultural and socio-political values imposed on wildlife can additionally shape management strategies and the management timeframe adopted. In this current study, the revenue gained from the medium-intensity density reduction strategy was predicted as $\$ 136$ per $\mathrm{km}^{2}$ over a 10 year timeframe. Considering the total area of agricultural-forest interface occurring within Tasmania (Fig. 1), upon extrapolation, these predictions demonstrate the potential for \$AU 1 million in revenue to be gained from harvesting operations across one Australian state, over a 10 year management period. However, the management of native and endemic pest species within Tasmania has attracted considerable socio-political opposition as these species concurrently have high conservation and biodiversity value (e.g. Coleman et al., 2006; Wiggins et al., 2010).

In situations where density reduction is being considered for the management of a pest species, or where the operational harvest of a species occurs, we propose that initial planning stages be guided by the use of spatially explicit decision support tools such as STAR, which can act as a predictive tool for the selection of an appropriate density reduction target, taking into account situation- and site-specific features including resource availability (i.e. time, budget), logistical constraints (i.e. whole- versus partialsite access), habitat features and management objectives (i.e. damage mitigation, integrated management approaches). The use of demographic models of population growth has been identified as one of the most commonly used measures for assessing 
the sustainable management of wildlife populations (Weinbaum et al., 2012). An additional factor that offers to strengthen the selection of simulated density reduction targets is the estimation or quantification of damage intensity resulting from various densities of the target pest population. While the measurement of this factor was outside the original scope of our empirical data collection (see Wiggins et al., 2010; McMahon et al., 2011), upon collection this information can be inputted into STAR for the continued updating of study-specific features and the resulting improvement of model output interpretation (McMahon et al., 2010).

Spatially explicit models such as those used in STAR can provide comparative density reduction outcomes and revenue-based harvesting potential to guide management planning efforts. It should be noted, however, that as a modelling-based decision support tool, outcomes will be influenced by input values which are variable in nature and may be influenced at a highly-localised scale. While the use of statistical approaches (i.e. Bayesian inference) can aide in improving model performance, the objective of this research was to provide a case study to demonstrate the applications of an accessible, user-friendly decision support tool for which data collection and input techniques are easy to perform, model output is easy to understand and highly adaptable to specific situations.

\section{Conclusions}

Human-wildlife conflicts can arise within landscapes modified and developed for management purposes. While the management of native or endemic pest species may attract considerable socio-political opposition (e.g. see Clarke and Ng, 2006, Richardson, 2012), density reduction approaches to wildlife management are likely to remain important control options in the quest for maintaining species' abundances, given their broad-scale accessibility by land managers and their cost-effectiveness (Porter et al., 1991; McNulty et al., 1997; Wiggins et al., 2010). Decision support tools such as STAR offer an approach in which management programmes can be developed to maximise the agricultural/utilitarian outcome by reducing the minimum number of animals for maximum exclusion, thus reducing the impact on the broader endemic population (see also McMahon et al., 2010). When developing a wildlife management strategy, we recommend that initial planning stages be guided by the use of a spatially explicit model such as STAR, which can act as a predictive tool in strategic management planning and contribute to synergising modelling, monitoring and management efforts (Chee and Wintle, 2010). STAR can be accessed by researchers and land managers alike to facilitate the adoption of strategic management planning with relative ease and transparency. A key feature of STAR is the facility to input and update information easily, making it a truly adaptive management tool where site-specific information can be fed back into the model for situation-based projections and improved land-use decisions can be made (McCarthy and Possingham, 2007).

Acknowledgements. We thank the Tasmanian Community Forest Agreement: Alternatives to 1080 Programme for project funding and the University of Tasmania and Charles Darwin University for inkind project support. We thank Greg Blackwell of the Game Management Services Unit and Garth Bennett of Forestry Tasmania for invaluable knowledge and assistance with data collection. We thank Dr Nicholas Beeton for model output validation and Dr Grant Williamson for the development of Figure 1. We also thank Dr Michael Perring, Scott Nicols, John Evans, Jo McMillan, Clare Brooker, Helen 
Stephens, Dr Natalia Atkins and Dr Peter Blain who assisted with data collection. We are especially grateful to Trevor Hall and Barry Whiting for property access. Approval for research was granted by the University of Tasmania Animal Ethics Committee (Permit A9895) and the Tasmanian Parks and Wildlife Service (Permit FA08122).

\section{REFERENCES}

[1] Bayliss, P., Yeomans, K.M. (1989): Distribution and abundance of feral livestock in the Top End of the Northern Territory (1985-86), and their relation to population control. Wildlife Research 16: 651-676.

[2] Bradshaw, C.J.A., Brook, B.W. (2007): Ecological-economic models of sustainable harvest for an endangered but exotic meagherbivore in northern Australia. - Natural Resource Modeling 20: 129-156.

[3] Bradshaw, C.J.A., Field, I.C., Bowman, D.M.J.S., Haynes, C., Brook, B.W. (2007): Current and future threats from non-indigenous animal species in northern Australia: a spotlight on World Heritage Area Kakadu National Park. - Wildlife Research 34: 419436.

[4] Buckley, Y.M., Rees, M., Paynter, Q., Lonsdale, M. (2004): Modelling integrated week management of an invasive shrub in tropical Australia. - Journal of Applied Ecology 41: 547-560.

[5] Bulinski, J., McArthur, C. (1999): An experimental field study of the effects of mammalian herbivore damage on Eucalyptus nitens seedlings. - Forest Ecology and Management 113: 241-249.

[6] Calaby, J.H., Grigg, G.C. (1989): Changes in Macropodoid Communities and Populations in the Past 200 Years, and the Future. - In: Grigg, C.G., Jarman, P., Hume, I. (eds.) Kangaroos, Wallabies and Rat-kangaroos, Second Ed., Surrey Beatty and Sons, Sydney.

[7] Caughley, G. (1985): Harvesting of Wildlife: Past, Present and Future. - In: Beasom, S.L., Roberson, S.F. (eds.) Game Harvest Management. Caesar Kleberg Wildlife Research Institite, Kingsville.

[8] Chapin, F.S., Zavaleta, E.S., Eviner, V.T., Naylor, R.L., Vitoused, P.M., Reynolds, H.L., Hooper, D.U., Lavorel, S., Sala, O.E., Hobbie, S.E., Mack, M.C., Diaz, S. (2000): Consequences of changing biodiversity. - Nature 405: 234-242.

[9] Chee, Y.E., Wintle, B.A. (2010): Linking modelling, monitoring and management: an integrated approach to controlling overabundant wildlife. - Journal of Applied Ecology 47: 1169-1178.

[10] Clark, M., Ng, Y.K. (2006): Population dynamics and animal welfare: issues raised by the culling of kangaroos in Puckapunyal. - Social Choice and Welfare 27: 407-422.

[11] Coleman, J.D., Montague, T.L., Eason, C.T., Statham, H.L. (1997:. The management of problem browsing and grazing mammals in Tasmania. Landcare Research Contract Report LC9596/106. - Browsing Animal Research Council, Hobart.

[12] Coleman, J.D., Pech, R., Warburton, B., Forsyth, D. (2006): Research into Alternatives to the Use of 1080 for the Management of Browsing Damage by Vertebrates in Tasmania. Landcare Research Contract Report LC0506/144. - Department of Primary Industries and Water, Hobart.

[13] Coulson, G. (2009): Behavioural ecology of red and grey kangaroos: Caughley's insights into individuals, associations and dispersion. - Wildlife Research 36: 57-69.

[14] Coulson, T., Guinness, F., Pemberton, J., Clutton-Brock, T. (2004): The demographic consequences of releasing a population of red deer from culling. Ecology 85: 411-422.

[15] Day, T., MacGibbon, R. (2007): Multiple-species Exclusion Fencing and Technology for Mainland Sites. - In: Witmer, G.W., Pitt, W.C., Fagerstone, K.A. (eds.) Managing Vertebrate Invasive Species: Proceedings of an International Symposium. USDA/APHIS/WS, National Wildlife Research Center, Fort Collins. 
[16] DPIPWE Density Indices. (2009): Wallaby Density Indicies 2005-2008. - Wildlife Management Branch, Department of Primary Industries, Parks, Water and Environment, Hobart.

[17] Edwards, G.P., Croft, D.B., Dawson, T.J. (1996): Competition between red kangaroos (Macropus rufus) and sheep (Ovis aries) in the arid rangelends of Australia. - Australian Journal of Ecology 21: 165-172.

[18] Edwards, G.P., Pople, A.R., Saalfeld, K., Caley, P. (2004): Introduced mammals in Australian rangelands: Future threats and the role of monitoring programmes in management strategies. - Austral Ecology 29: 40-50.

[19] Figueirido, B., Janis, C.M. (2011): The predatory behaviour of the thylacine: Tasmanian tiger or marsupial wolf? - Biology Letters 7: 937-940.

[20] Fitzpatrick, M.C., Preisser, E.L., Ellison, A.M., Elkinton, J.S. (2009): Observer bias and the detection of low-density populations. - Ecological Applications 19: 1673-1679.

[21] Gibbs, J.P., Snell, H.L., Causton, C.E. (1999): Effective monitoring for adaptive wildlife management: lessons from the Galápagos Islands. - Journal of Wildlife Management 63: 1055-1065.

[22] Hamede, R.K., McCallum, H., Jones, M. (2013): Biting injuries and transmission of Tasmanian devil facial tumour disease. - Journal of Animal Ecology 82: 182-190.

[23] Haule, K., Johnsen, F., Maganga, S. (2002): Striving for sustainable wildlife management: the case of Kilombero Game Controlled Area, Tanzania. - Journal of Environmental Management 66: 31-42.

[24] le Mar, K., McArthur, C. (2001): Changes in marsupial herbivore densities in relation to a forestry 1080-poisoning operation. - Australian Forestry 64: 175-180.

[25] Lurz, P.W.W., Shirley, M.D.F., Geddes, N. (2008): Monitoring low density populations: a perspective on what level of population decline we can truly detect. - Animal Biodiversity and Conservation 31, 29-39.

[26] McCarthy, M.A., Possingham, H.P. (2007): Active adaptive management for conservation. - Conservation Biology 21: 956-963.

[27] McMahon, C.R., Bester, M.N., Hindell, M.A., Brook, B.W., Bradshaw, C.J. (2009): Shifting trends: detecting environmentally mediated regulation in long-lived marine vertebrates using time-series data. - Oecologia 159: 69-82.

[28] McMahon, C.R., Brook, B.W., Collier, N., Bradshaw, C.J.A. (2010): Spatially explicit spreadsheet modelling for optimising the efficiency of reducing invasive animal density. - Methods in Ecology and Evolution 1, 53-68.

[29] McMahon, C.R., Buscot, M-J., Wiggins, N.L., Collier, N., Maindonald, J.H., McCallum, H.I., Bowman, D.M.J.S. (2011): A Two-Phase Model for Smoothly Joining Disparate Growth Phases in the Macropodid Thylogale billardierii. - PLoS ONE 6(10): e24934.

[30] McMahon, C.R., Wiggins, N.L., French, V., McCallum, H.I., and Bowman, D.M.J.S. (2013). Capture myopathy in the Tasmanian pademelon. - Animal Welfare 22: 1-4.

[31] McNulty, S.A., Porter, W.F., Mathews, N.E., Hill, J.A. (1997): Localized management for reducing white-tailed deer populations. - Wildlife Society Bulletin 25: 265-271.

[32] Porter, W.F., Mathews, N.E., Underwood, H.B., Sage, R.W., Behrend, D.F. (1991): Social organization in deer: implications for localized management. - Environmental Management 15: 809-814.

[33] Richardson, K. (2012): Australia's Amazing Kangaroos - Their Conservation, Unique Biology and Coexistence with Humans. - CSIRO Publishing, Collingwood.

[34] Rounsevell, D.E., Taylor, R.J., Hocking, G.J. (1991): Distribution records of native terrestrial mammals in Tasmania. - Wildlife Research 18: 699-717.

[35] Shea, K., Amaraskare, P., Mangel, K.M., Moore, J., Murdoch, W.W., Noonburg, E., Parma, A.M., Pascual, M.A., Possingham, H.P., Wilcox, C., Yu, D. (1998): Management of populations in conservation, harvesting and control. - Trends in Ecology and Evolution 13: 371-375. 
[36] Soroush, P. (2010): Native herbivore becomes a key pest after dismantlement of a traditional farming system. - American Entomologist 56: 242-251.

[37] TASVEG 2005. (2005). TASVEG - The Tasmanian Vegetation Map v1.3. Tasmanian Vegetation Mapping Program (TVMP). - Resource Management and Conservation, Hobart. Available at: http://www.thelist.tas.gov.au/asdd/ANZTA0015000012.html [verified April 2005].

[38] Torstenson, W.L.F., Tess, M.W., Knight, J.E. (2002): Elk management strategies and profitability of beef cattle ranches. - Journal of Range Management 55: 117-126.

[39] Viggers, K.L., Hearn, J.P. (2005): The kangaroo conundrum: home range studies and implications for land management. - Journal of Applied Ecology 42: 99-107.

[40] Vitousek, P.M., Mooney, H.A., Lubchenco, J., Melillo, J.M. (1997): Human domination of Earth's ecosystems. - Science 277: 494-499.

[41] Weinbaum, K.Z., Brashares, J.S., Golden, C.D., Getz, W.M. (2013): Searching for sustainability: are assessments of wildlife harvests behind the times? - Ecology Letters 16: 99-111.

[42] Wiggins, N.L., Williamson, G.J., McCallum, H.I., McMahon, C.R., Bowman, D.M.J.S. (2010): Shifts in macropod home range in response to wildlife management interventions. - Wildlife Research 37: 379-391.

[43] Wiggins, N.L., Bowman, D.M.J.S. (2011): Macropod habitat use and response to wildlife management interventions in an agricultural-forest habitat mosaic in northeast Tasmania. - Wildlife Research 38: 103.

[44] Wilson, G.R., Edwards, M.J. (2008): Native wildlife on rangelands to minimize methane and produce lower-emission meat: kangaroos versus livestock. - Conservation Letters 1:119-128.

\section{Appendix}

Appendix: A $2 \times 2 \mathrm{~km}$ cell grid of the study site, using habitat features derived from habitat surveys (Wiggins et al., 2010) and TASVEG (2005). This grid formed the basis of a vector grid which was created for use in the STAR model.

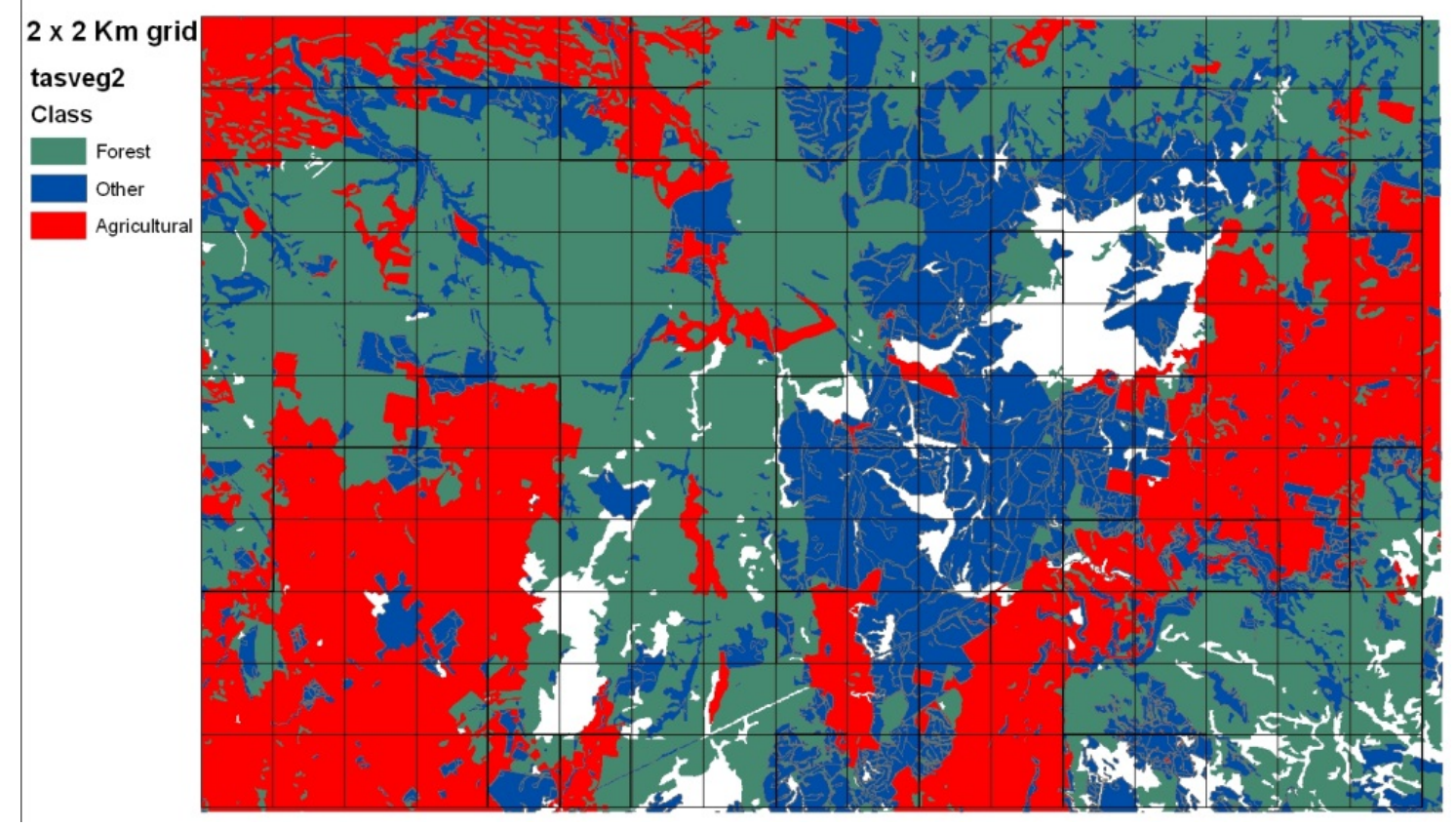

